\title{
Comparative Analysis of the Effect of Thermal Cycling on Fatigue Behavior of Low and Medium Carbon Steel
}

\author{
Agbadua Segun Afokhainu \\ National Engineering Design Development Institute, Nnewi, Nigeria \\ Email address: \\ afokhainu@yahoo.com
}

\section{To cite this article:}

Agbadua Segun Afokhainu. Comparative Analysis of the Effect of Thermal Cycling on Fatigue Behavior of Low and Medium Carbon Steel. American Journal of Mechanical and Industrial Engineering. Vol. 2, No. 3, 2017, pp. 130-136. doi: 10.11648/j.ajmie.20170203.13

Received: September 25, 2016; Accepted: October 19, 2016; Published: February 21, 2017

\begin{abstract}
This paper presents the technique with which Low frequency thermal cycling tests were carried out on two carbon steel. The steels used are low and medium carbon steel, the compositional analysis was done to ascertain the percentage of carbon the as-received materials contain, and the micrograph of the samples was done using acuscope photomicrograph with a magnification of X400. The heating of the samples was done in a carbon muffle furnace and the test was done at predetermined ranges of thermal cycling temperatures. The specimen were machined to a precise gage length and diameter and the test was performed with the use of Avery Dennison (Avery model 7305) which has a curve with which the relationship between the dial gage reading and the imposed torque was established. The results obtained from the machine were the readings for maximum bending moment and cycles to failure, which were converted to get the applied bending stress. On the final analysis medium carbon steel prove to be a suitable material for design of machine that could undergo thermal cycling in service condition beyond $230^{\circ} \mathrm{C}$.
\end{abstract}

Keywords: Thermal Cycling, Fatigue Behaviour, Low and Medium Carbon Steel

\section{Introduction}

Steel is an alloy of iron and carbon that has been in used for various constructions ranging from structural to mechanical do experience various types of failures in service amongst is fatigue. Interest in comparing the fatigue failure is to determine the better of the materials that could be used in the design of a car exhaust. Fatigue failure is a phenomenon that leads to fracture under repeated or fluctuating stresses that are less than the tensile strength of the material. The effect of thermal cycling of a material cannot be trivialized because of its importance to design and manufacturing engineers.

There are many forces that causes fatigue failure to a material in service, they are numerous, but few shall be mentioned in this paper, some of which are vibrations and thermal, although thermal cycling will be discussed. Fatigue failure is becoming progressively more prevalent as technology is advancing and rolling out equipment such as automobiles, aircrafts, compressors, pumps turbines boiler and a host of others subjected to repeated loading and vibration, until today. It is often stated that fatigue account for at least 90 percent of all service failures due to mechanical causes and the fractured surface of a fatigue caused failure is usually normal to the direction of the principal tensile stress on a macroscopic scale. Medium carbon steels find wide applications in the manufacture of low cost gears, axles, shafts, fasteners and other similar components ([1] and [2]). These components do have high strength together with adequate toughness to give resistance to crack propagation and the measure of resistance to crack propagation is termed as fracture toughness [3].

Thermal cycling of a material is the subjection of the materials to cycles of localized heating to high temperature with a flame or by other means followed by cooling with compressed air or other gas. In 1945, [4] commented that progress with methods of fatigue analysis had been slow because of lack of basic information on material and more importantly no method of handling (i.e. the direct use of an S-N curve). Microstructural analysis of the as-received specimens subjected to thermal cycling indicates that reduction of ferrite brings increase in the carbon content which increases the strength of the material thus making the material brittle in nature and decomposition and grain growth are responsible for the reduction in hardness while cohesion of ferrite and pearlite and grain boundary separation are 
responsible for the reduction in the modulus of elasticity upon thermal cycling. It was reported by [5] that thermal cycling is followed by the formation of a larger number of fine cracks $(0.1-1.0 \mathrm{~mm}$ long $)$ on the surface of the specimen and these cracks grow with increasing number of thermal cycle. The birth of this research is to be able to predict the useful life of a machine part made with low and medium carbon steel and the performance of the material at various service conditions. In this paper cyclic thermal loading is applied to a fully constrained specimen. The following are the two types of thermal cycling:

- low frequency thermal cycling

- high frequency thermal cycling

This paper tends to look at the low frequency thermal cycling in which the time involved is in milli-seconds and the heating and cooling are influenced by thermal inertia of the system under consideration.

The research was conducted using Acuscope photomicrograph with magnification of X400 and carbonmuffle furnace for heating and the cooling was done in the air, the air cooling could also have caused corrosion fatigue to set-in.

\section{Experimental Techniques and Methods}

The steels used in the present study were low carbon $\left(\mathrm{A}_{1}\right)$ and medium carbon $\left(\mathrm{A}_{2}\right)$ steel. The chemical compositions of these steels are given in table 1. The as-received material came in the form of rolled bars machined to a length of $50.9 \mathrm{~mm}$ and a gage length with diameter of $5.2 \mathrm{~mm}$. Thermal cycling the as-received which contain different amount of carbon were held in the furnace at 120,360 and $500^{\circ} \mathrm{C}$ for 30minutes.

Table 1. The table showing the composition of the samples.

\begin{tabular}{lllllllll}
\hline & $\mathbf{C}$ & Si & Mn & Ni & Cr & Cu & Sn & S \\
\hline $\mathrm{A}_{1}$ & .2045 & .1589 & .5993 & .1066 & .0851 & .2880 & .0404 & .0444 \\
$\mathrm{~A}_{2}$ & .2790 & .1579 & .7299 & .1194 & .1505 & .1494 & .0087 & .0303 \\
\hline
\end{tabular}

The furnace used for this study was carbon-muffle furnace with an in-built thermocouple. The furnace was heated to the temperature of $120^{\circ} \mathrm{C}$ before the as-received were soaked for 30 minutes. Twenty-four samples were soaked in the furnace temperature of $120^{\circ} \mathrm{C}$ for 30 minutes. After heating for 30 minutes the materials were removed from the furnace for cooling, which was done in air. After cooling, six samples were taken for fatigue test and the remaining eighteen samples were taken back to the furnace for the second cycle of thermal treatment. Similar thing was done to complete the four cycles of thermal treatment at that temperature and for the subsequent temperatures the same approach was used. This process was done to both as-received materials. The cooling in air brings about stress relief to the specimen.

The fatigue testing machine that was used for the test is Avery Denison (Avery Model 7305). The revolution counter fitted to the motor records the number of stress cycles to failure $(\mathrm{N})$. When the specimen breaks the machine stopped automatically by a cut-out switch. The calibration curve supplied with the machine was used to show the relationship between dial gauge reading and imposed torque.

The following equation was used to calculate the bending stress.

$$
\sigma_{s}=\frac{M_{\max }}{W}
$$

$M_{\text {max }}=$ Maximum bending moment in $\mathrm{kgfcm}$

$\mathrm{W}=$ section modulus $\equiv I=\frac{\pi d^{3}}{32}$

$\mathrm{d}=$ specimen diameter $(\mathrm{mm})$

$\pi=3.142$

$\sigma_{s}=$ Bending stress $\left(\mathrm{MPa}\right.$ or $\left.\mathrm{KN} / \mathrm{m}^{2}\right)$

Maximum bending moment in $\mathrm{kgfcm}$ was converted to $\mathrm{KN}-\mathrm{m}$ by multiplying kgfem by $9.807 \times 10^{-2}$. The torques imposed was $10,30,40,50,100$ and $150 \mathrm{kgfcm}$ and Staircase method was used in imposing the torque. The bending test was performed at a frequency of $50 \mathrm{~Hz}(1400$ $\mathrm{rpm}$ ) for each specimen. The fatigue testing machine (Avery Denison) is shown in Fig. 1.

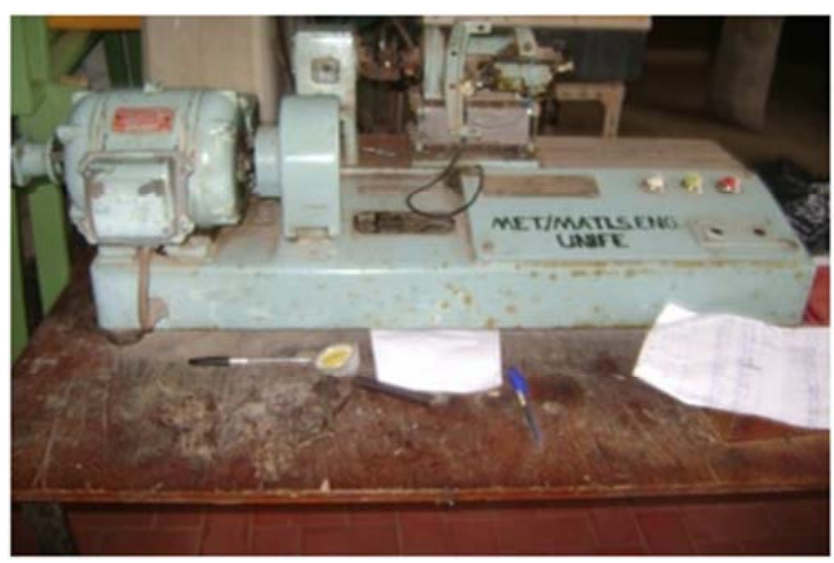

Fig. 1. Fatigue testing Machine (Avery Model 7305).

\section{Results and Discussions}

\subsection{Metallography}

The As-received materials ( $\mathrm{A}_{1}$ and $\mathrm{A}_{2}$ show ferrite-pluspearlite microstructure (Fig. 2 and 6). The pearlite is distributed uniformly but as irregularly shaped volumes embedded in the ferrite matrix (that is typical of a fine tempered structure) Fig. (3-5 and 7-9) reveals the microstructure of $A_{1}$ and $A_{2}$ steels which were thermally stressed. These micrographs show equi-axed bainite phase surrounding ferrite grains. The ferrite grains appear unchanged from these observed in the as-received material. 
The ferrite phase did not experience any structural change after quenching. On the other hand, it is observed on these micrographs that the volume fraction of bainite phase increases as carbon content.

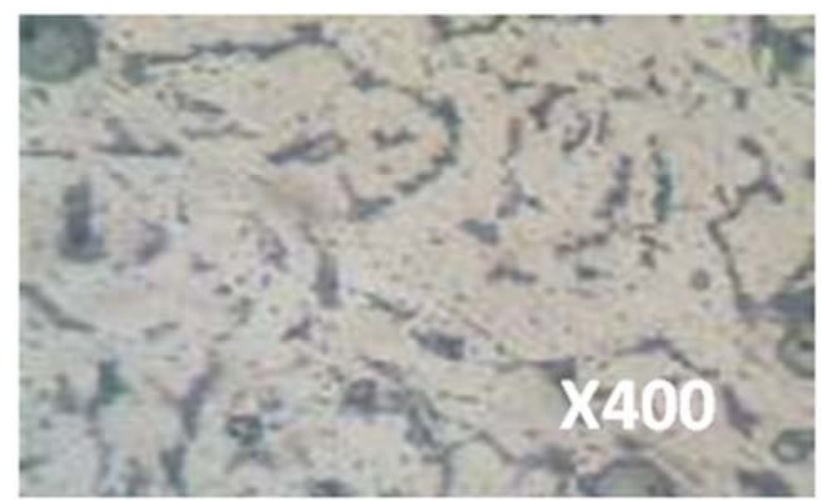

Fig. 2. Low carbon steel in air.

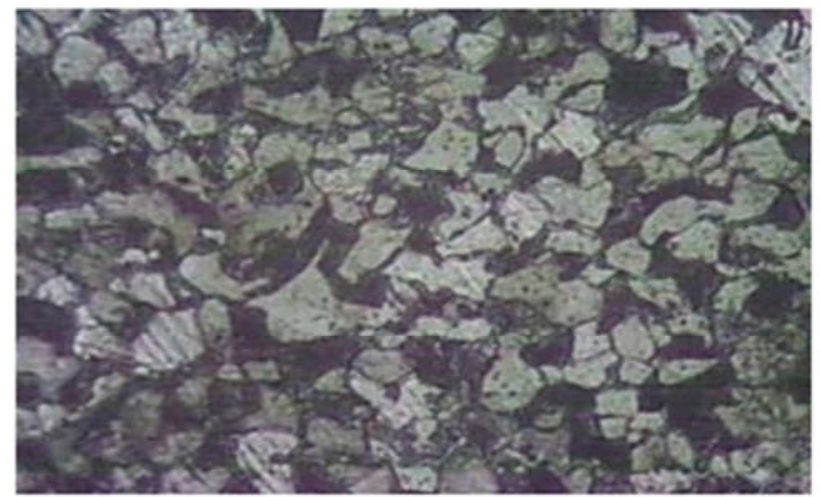

Fig. 3. Microstructure of $A_{l}$ at $120^{\circ} \mathrm{C}$.

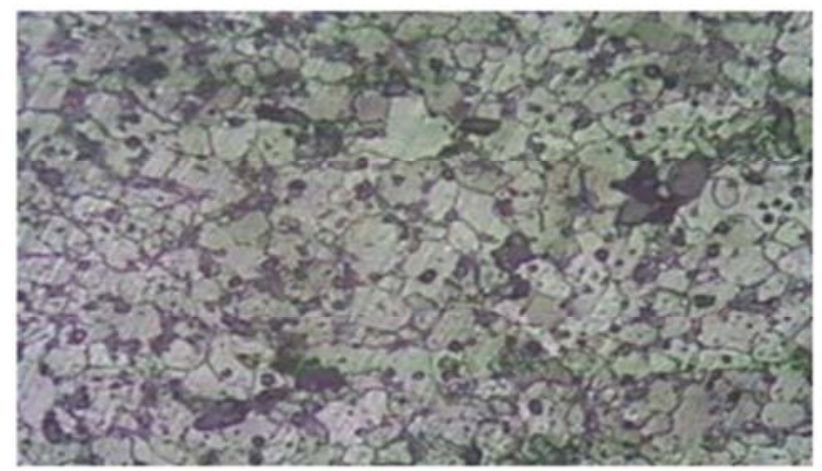

Fig. 4. Microstructure of $A_{l}$ at $360^{\circ} \mathrm{C}$.

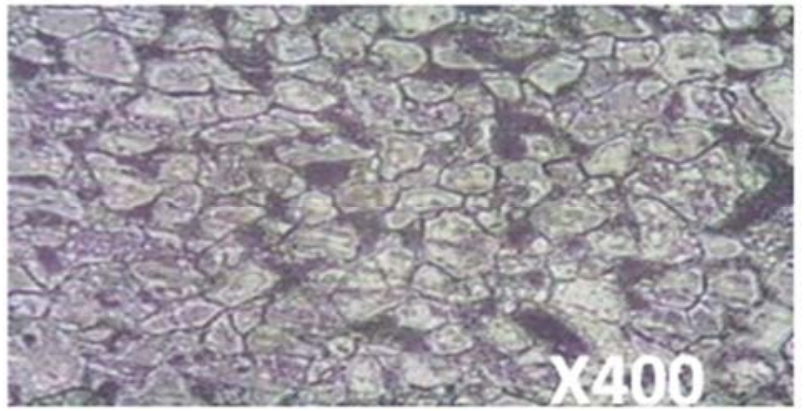

Fig. 5. Microstructure of $A_{1}$ at $500^{\circ} \mathrm{C}$.

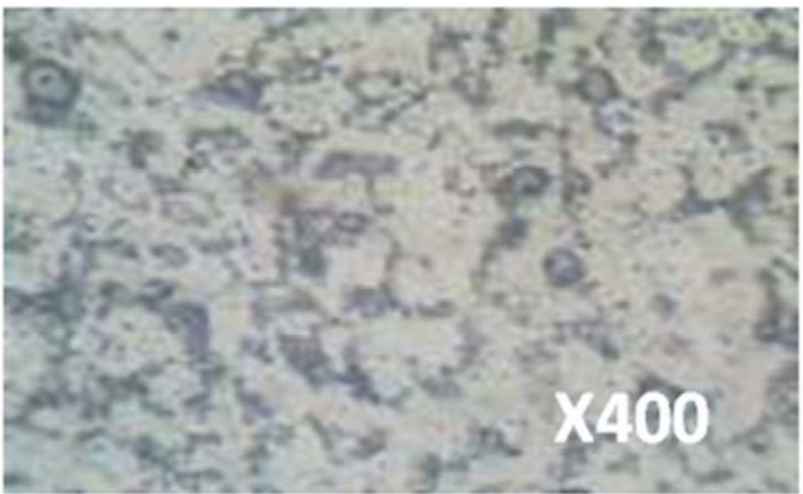

Fig. 6. Medium carbon steel in air.

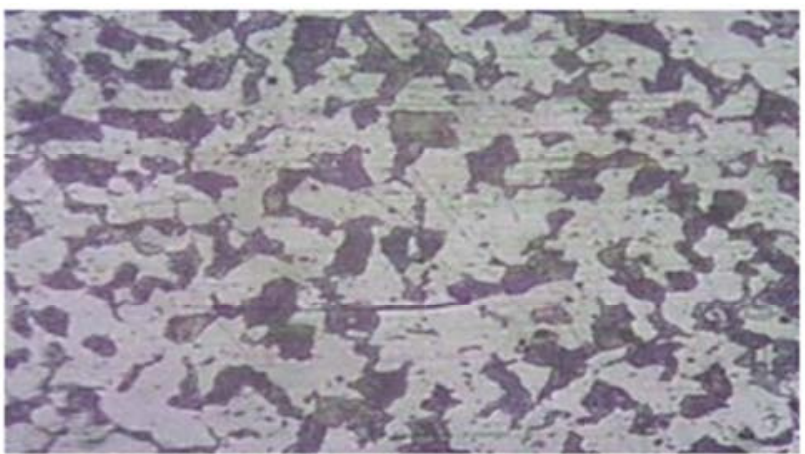

Fig. 7. Microstructure of $A_{2}$ at $120^{\circ} \mathrm{C}$.

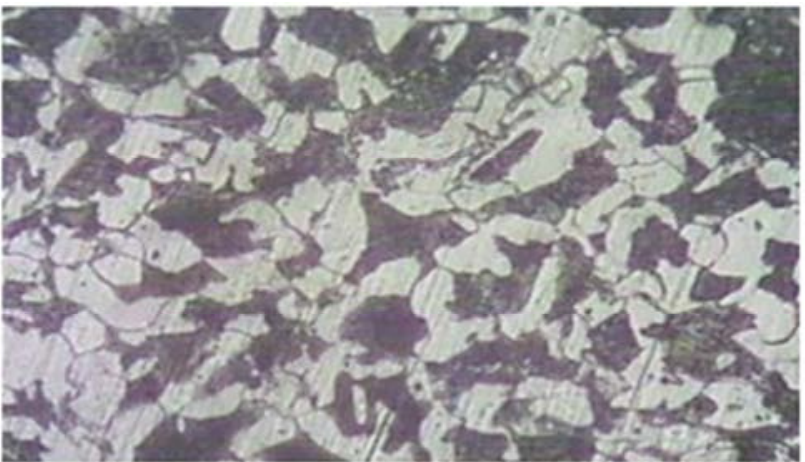

Fig. 8. Microstructure of $A_{2}$ at $360^{\circ} \mathrm{C}$.

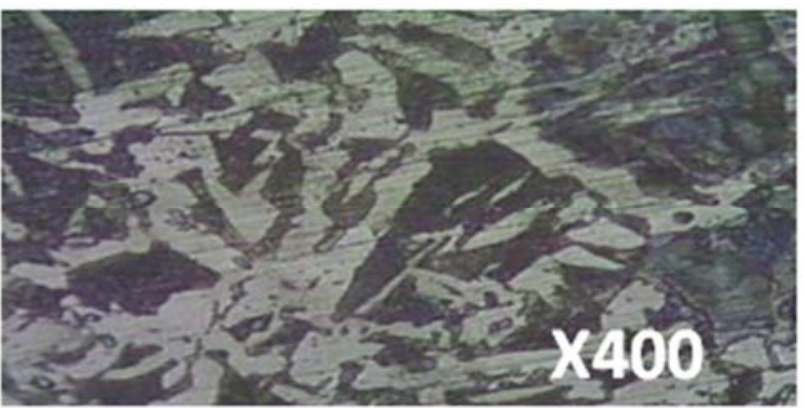

Fig. 9. Microstructure of $A_{2}$ at $500^{\circ} \mathrm{C}$.

\subsection{Discussion of Results}

The effect of thermal cycling on fatigue behavior of low and medium carbon steel were deduced from the plotted graphs and corroborated by the micrographs. At $120^{\circ} \mathrm{C}$ the graphs in 
Fig. 10 and 13 show the graphs of stress against no of cycles for the specimen. The graph shows that low carbon steel has good fatigue resistance up until the temperature of $220^{\circ} \mathrm{C}$, [6]. Low carbon steel has a better fatigue resistance between $120^{\circ}$ $220^{\circ} \mathrm{C}$ as a result of low carbide proportion present in the microstructure compared to the result of the micrograph in air and the carbide is evenly distributed with little inclusions as a result of heating to $120^{\circ} \mathrm{C}$. Figure 3 depicts the micrograph. While in the case of medium carbon steel it has higher percentage of carbide making the specimen harder and brittle this is depicted in Fig. 8. Although the fracture that took place in both specimens were ductile fracture.

At $360^{\circ} \mathrm{C}$, the low carbon steel has the lowest fatigue strength, this as a result of increased proportion of inclusion or impurities such as oxides and sulphides this is shown in Fig. 4. Medium carbon steel resistance to fatigue improves with cycling, the more cycles the better the fatigue resistance. Fig. 8, shows the microstructure of medium carbon steel at $360^{\circ} \mathrm{C}$, the micrograph shows the lamellar structure and it implies that the grains are fine texture. At the surface of the specimen you have more pearlite than the ferrite thus making it harder and the failure was a ductile type as evidenced from the surface. Detailed study of ductile fracture process shows that the central crack which forms early tends to concentrate the deformation at its tip in narrow bands of high shear strain, [3]. Crack growth in ductile fracture is essentially by a process of void coalescence, voids which are formed at inclusions second phase particles or fine oxides particles while in high purity metals voids do form at grain -boundary triple points [3]

At $500^{\circ} \mathrm{C}$, low carbon steel has a better fatigue resistance than at $360^{\circ} \mathrm{C}$ where it has its lowest fatigue resistance. It has the highest resistance at the fourth cycle of thermal cycling except at $360^{\circ} \mathrm{C}$. This is a result of strain hardening. The micrograph in Fig. 8 shows that the grains are coarse and at the south west of the Fig. 5, it equally shows a river branching meaning the fracture could be transgranular type. In Fig. 9, the structure is dendritic and the specimen failed in ductile form. The specimen fracture toughness and ductility are at the peak at the fourth cycle of thermal cycling. Fig. 17 and 18 show the plot of fatigue resistance against numbers of thermal cycles (n) while Fig. 19 and 20 show the plot of fatigue resistance against numbers of cycles to failure

Fig. 17, show the behavior of low carbon to thermal cycling as not consistent and that it is sinusoidal this further strengthen the fact that low carbon steel is not heat treatable, [6]. Fig. 18, show the behavior of medium carbon steel to thermal cycling as persistent and it equally shows that fatigue resistance improves with cycles of thermal treatment at different temperatures, while Fig. 17, Shows that fatigue resistance of low carbon steel in thermal cycling as incoherent. Although at high temperature test there is no steel that has apparent tendency for the fatigue limit to be developed. [6] has it that the fatigue strength of low carbon steel reaches a maximum value at the temperature range of $200-300^{\circ}$ and the temperature at which peak fatigue strength occurs being dependent upon the frequency at which the alternating stress is applied.

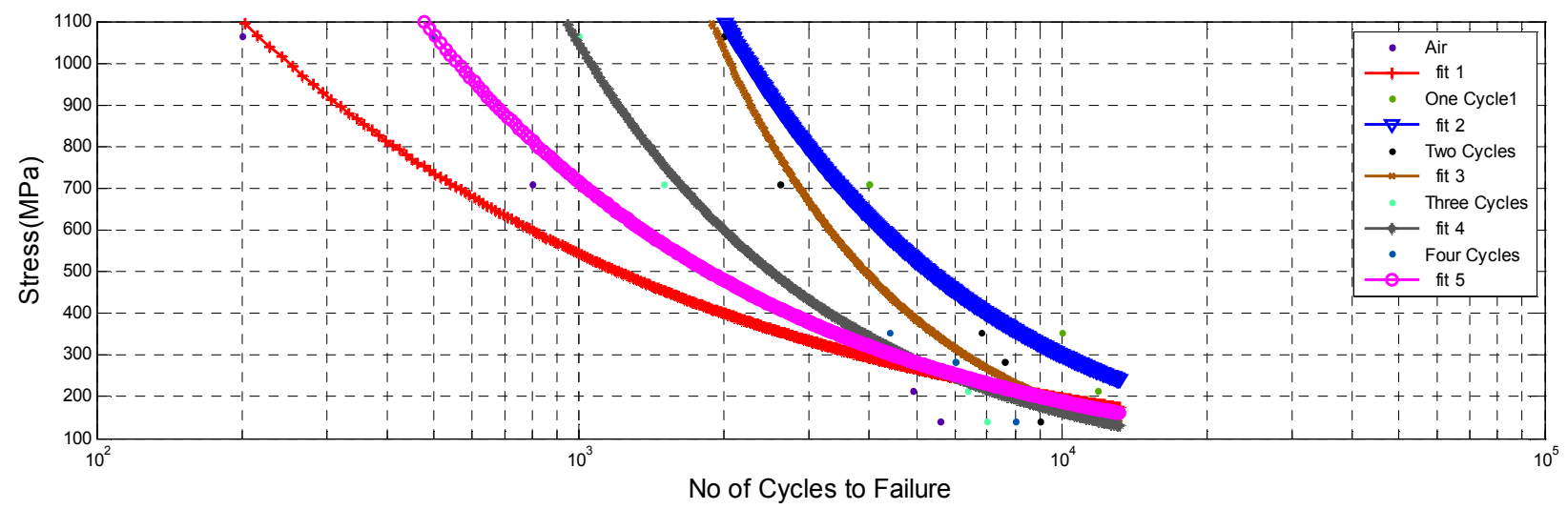

Fig. 10. S-N curves for low carbon Steel at different thermal cycles at $120^{\circ} \mathrm{C}$.

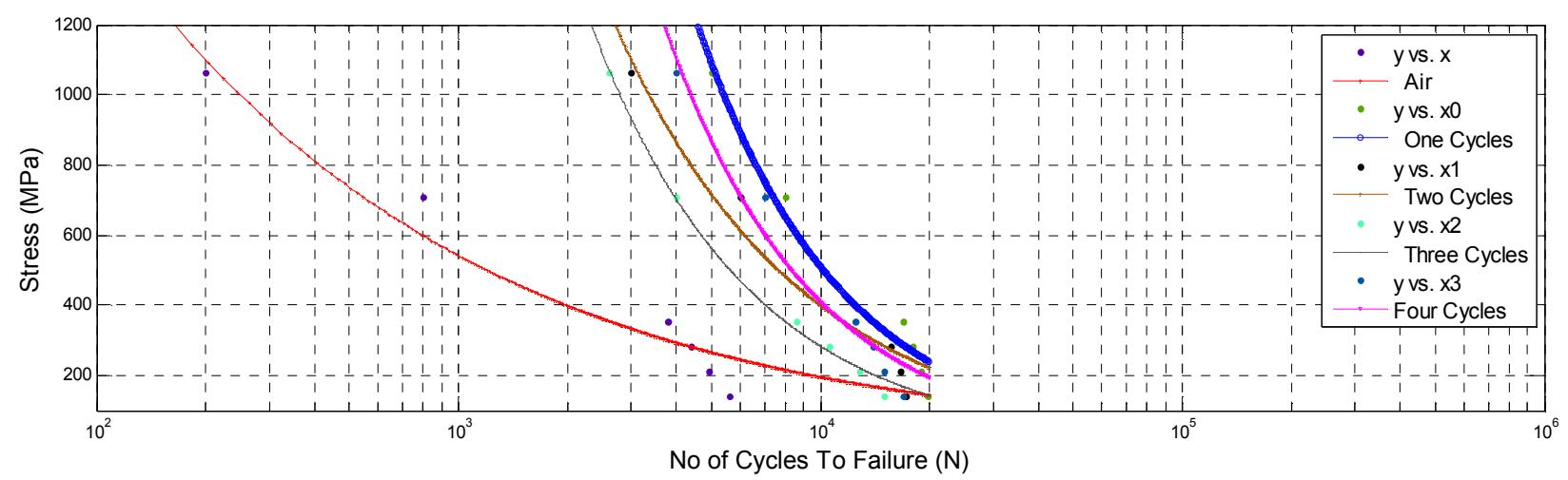

Fig. 11. S-N Curves for Low Carbon Steel at different thermal cycle at $360^{\circ} \mathrm{C}$. 


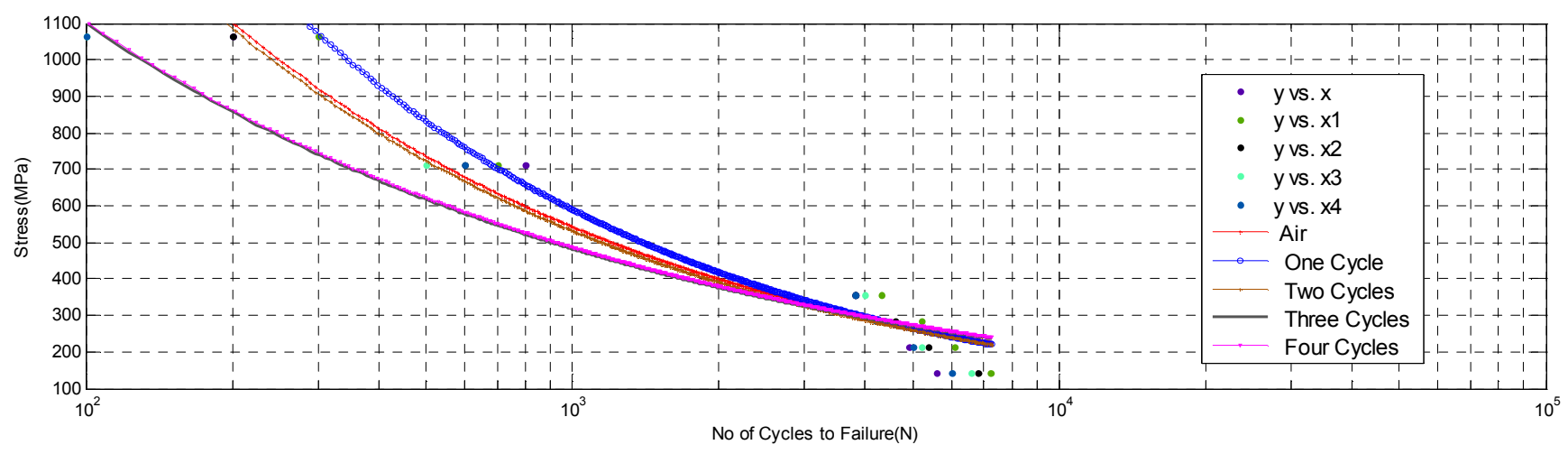

Fig. 12. S-N Curves for Low Carbon Steel at different thermal cycles at $500^{\circ} \mathrm{C}$.

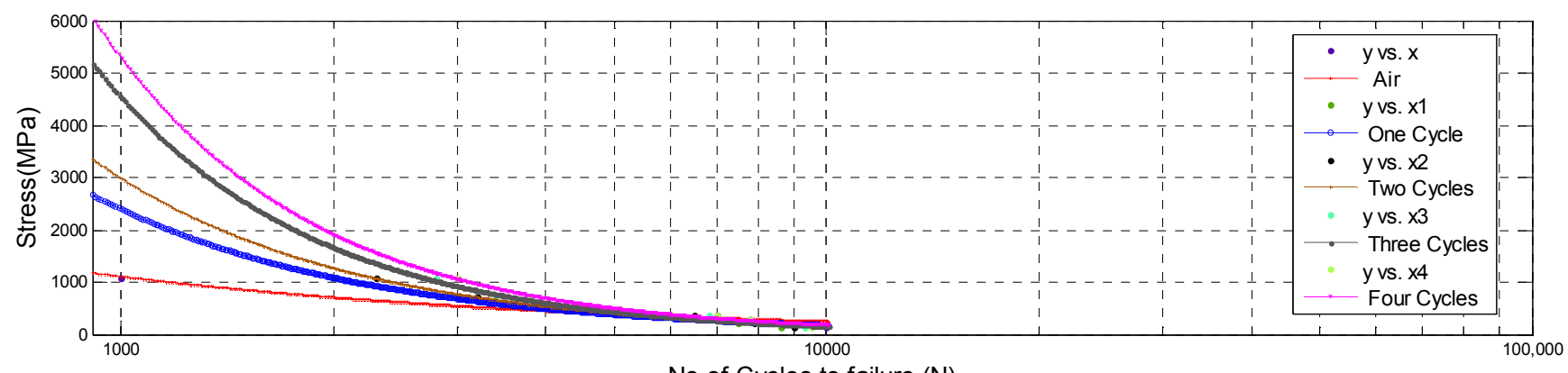

No of Cycles to failure (N)

Fig. 13. S-N curves for medium carbon steel at different thermal cycles at $120^{\circ} \mathrm{C}$.

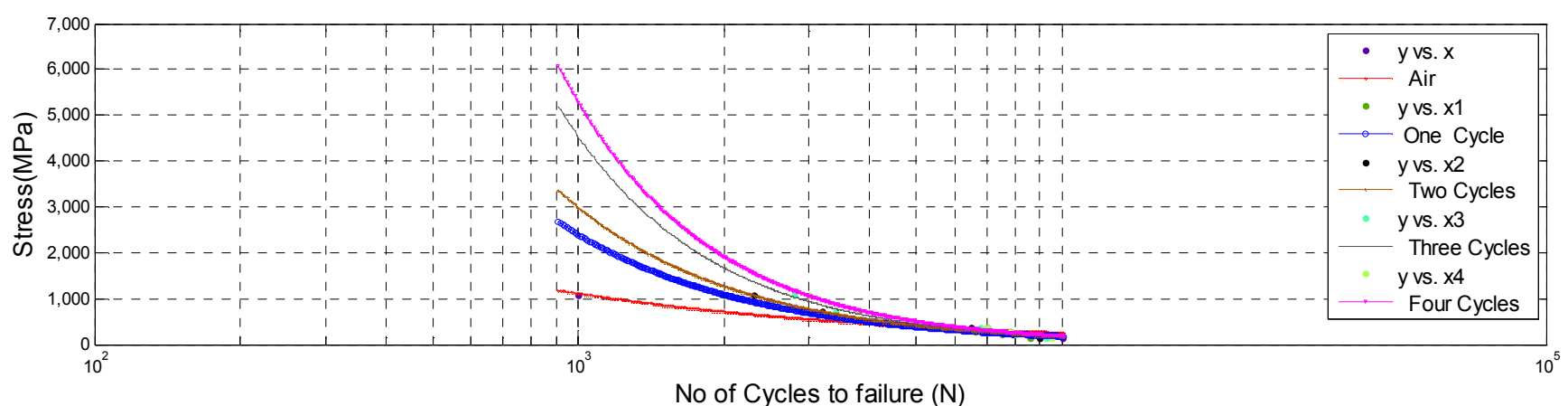

Fig. 14. S-N curves for medium carbon steel at different thermal cycles at $360^{\circ} \mathrm{C}$.

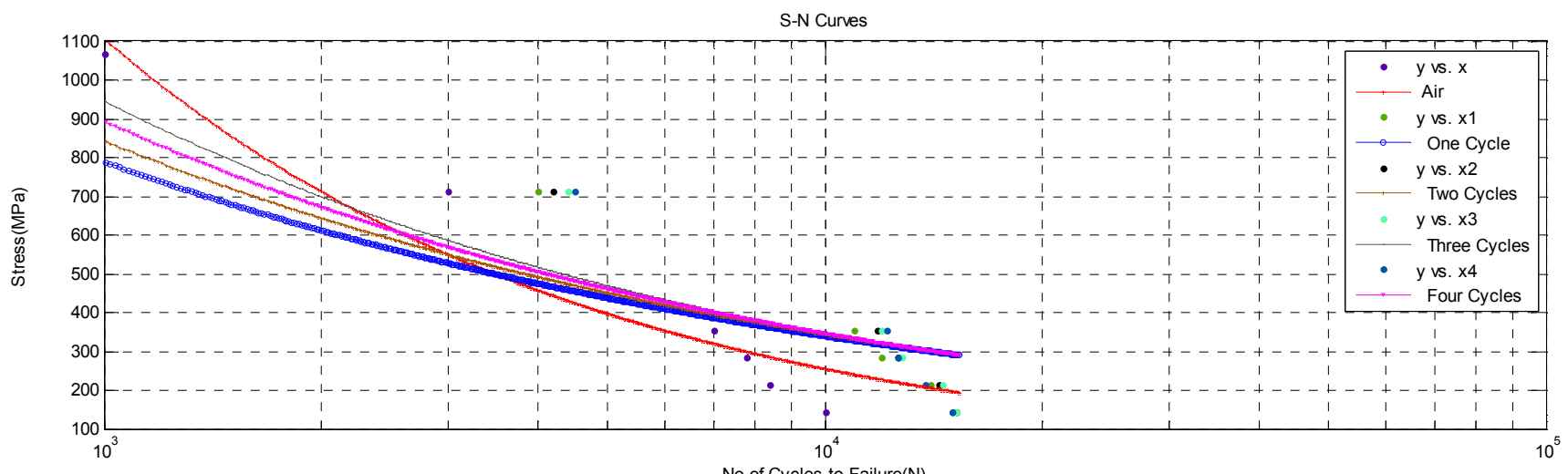

Fig. 15. S-N curves for medium carbon steel at different thermal cycles at $500^{\circ} \mathrm{C}$. 


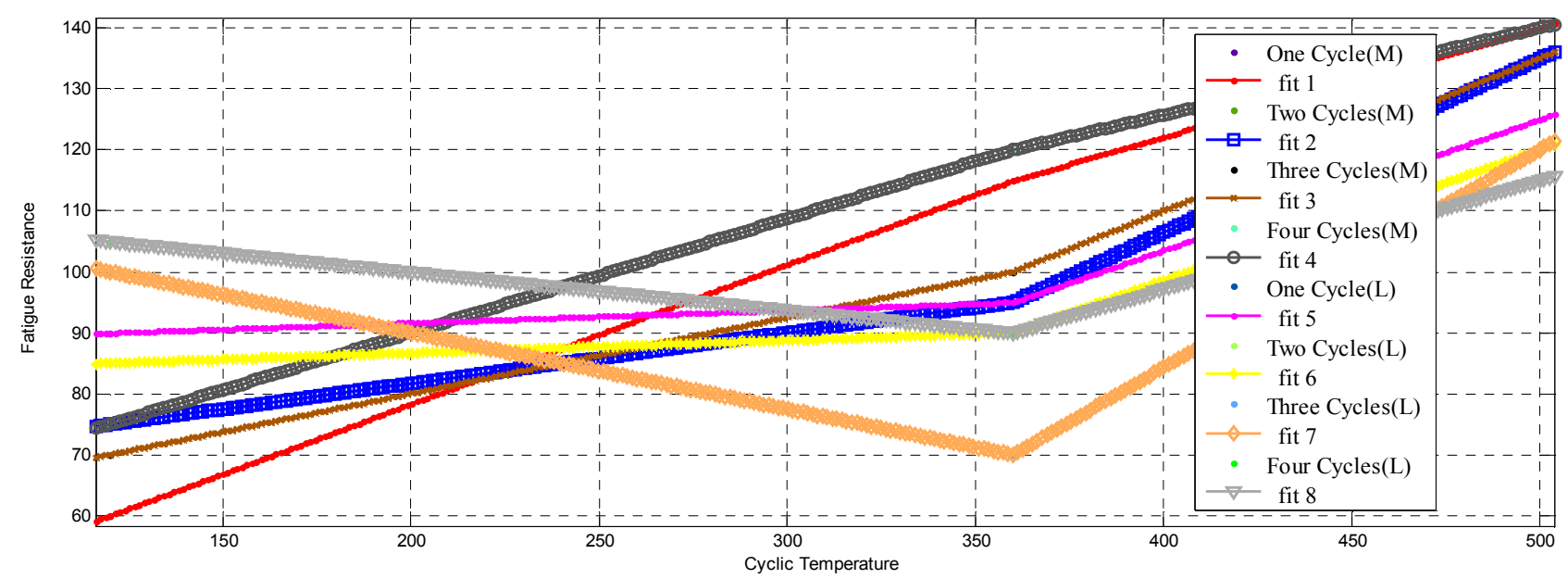

Fig. 16. The graph of fatigue resistance against cyclic temperature.

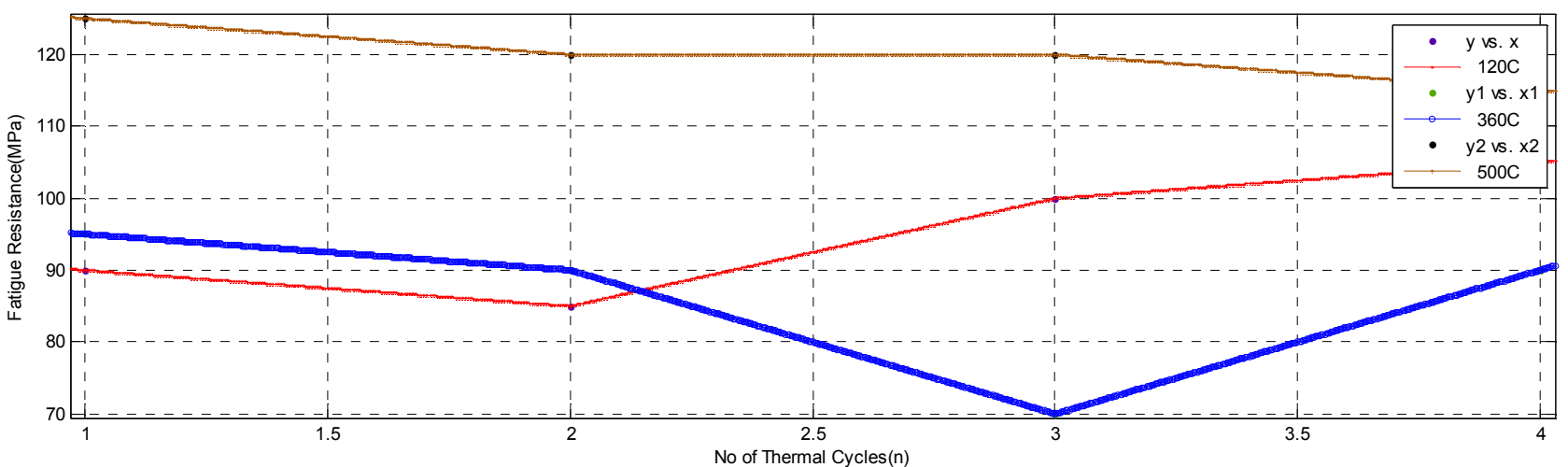

Fig. 17. Fatigue Resistance (MPa) against No of Thermal Cycles(n) of low carbon steel.

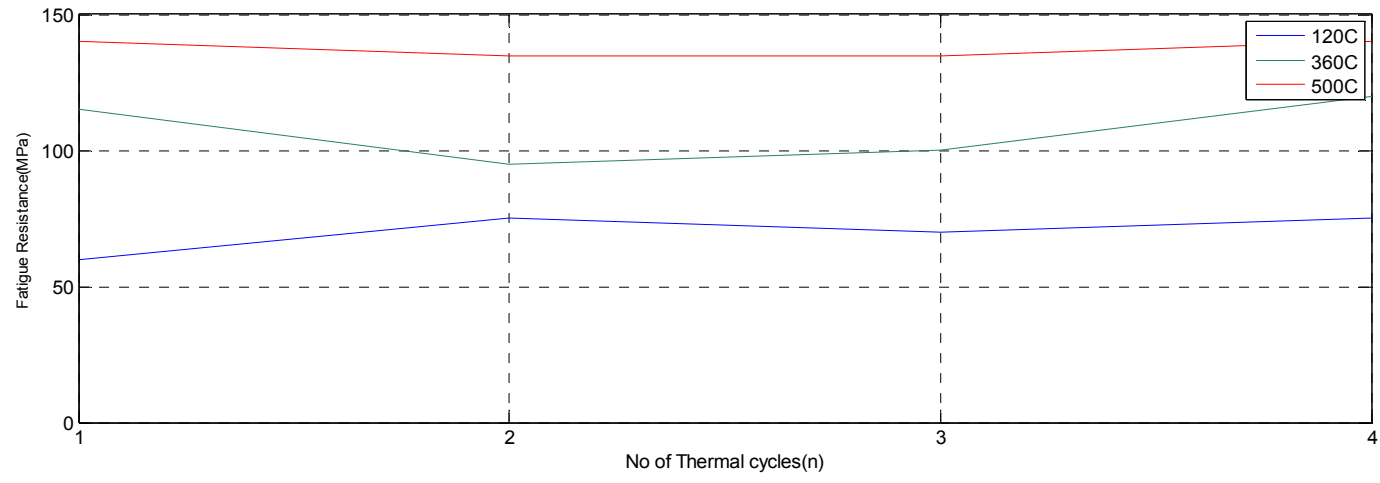

Fig. 18. Fatigue Resistance (MPa) against No of Thermal Cycles(n) of Medium carbon steel.

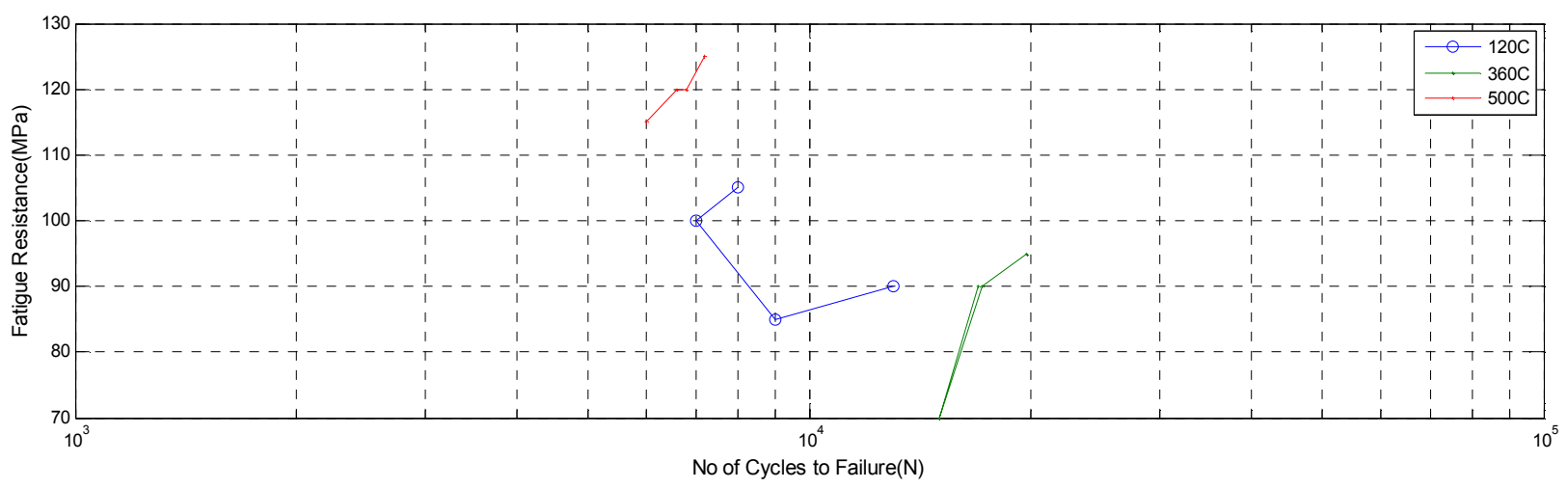

Fig. 19. Fatigue Resistance (MPa) against No of Cycles to Failure (N) of Low Carbon Steel at different cyclic Temperature. 


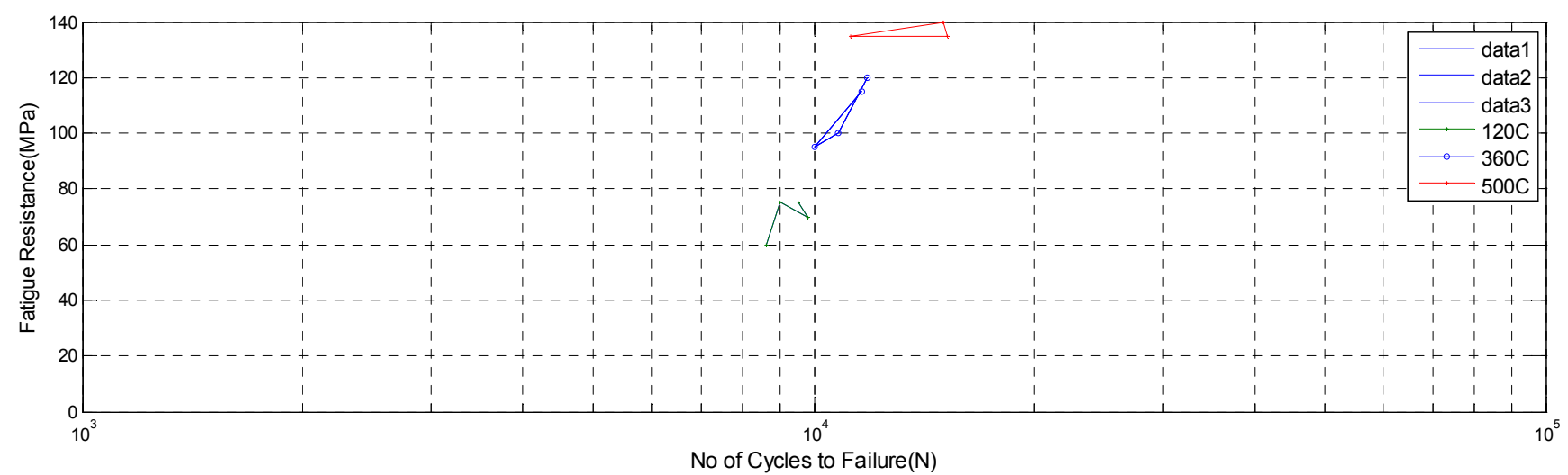

Fig. 20. Fatigue Resistance (MPa) against No of Cycles to Failure (N) of Medium Carbon Steel at different cyclic Temperature.

\section{Conclusions}

From the investigation, the following conclusions were obtained.

1) When selecting a material for use under fatigue conditions it may be better to select one which shows a fatigue limit, instead of the one that exhibits an endurance limit. For instance low carbon has fatigue limit between $20^{\circ} \mathrm{C}-220^{\circ} \mathrm{C}$ while medium carbon steel shows better fatigue resistance at temperature increase. On this note low carbon steel should not be selected for use in design and construction of boilers, exhaust and furnace.

2) It was also discovered that fatigue performance is a function of the material ductility.

\section{References}

[1] Rollason E. C. (1976), Metallurgy for Engineers.

[2] William D. Callister Materials science and Engineering $5^{\text {th }}$
Edition, pp 209-222.

[3] Dieter G. E. (1988), Mechanical Metallurgy, SI Metric Edition, McGraw- Hill. pp 473-8, 414 \& 395.

[4] Miner M. A. (1945), cumulative damage in fatigue trans ASME, 67.

[5] Prokopenko A. V. (1984) "A method of evaluation of the life of a structure in programmed cyclic loading" pp 45-50.

[6] Hearn E. J. (1997), The mechanics of elastic and plastic deformation of solids and structural materials. pp 441-457 \& 491.

[7] Rajar, T. V. and et al (1988), Heat treatment principle and techniques.

[8] Avner. S. H. (1974), Introduction to physical Metallurgy. pp 643.

[9] Roehrig, K., (1978). Thermal fatigue of gray and ductile irons. AFS Trans. 86: 75-88.

[10] M. Tayanc, A. Aytac, A. Bayram: The Effect of Carbon Content on Fatigue Strength of Dual-Phase Steels. Materials and Design 28, 2007, 1827-1835. 